$\xi=-$ 圆

\title{
Host-Guest Expectations of Service Quality at Small Island Settings: A Cross-Cultural Approach
}

\author{
Fathilah Ismail $^{1}$, Ahmad Puad Mat Som ${ }^{2 *}$, Siti Falindah Padlee', Wan Mariam Wan Abdullah ${ }^{1}$ \\ ${ }^{1}$ School of Maritime Business and Management, Universiti Malaysia Terengganu, 21300 Kuala Nerus, Terengganu, Malaysia \\ ${ }^{2}$ Faculty of Applied Social Sciences, Universiti Sultan Zainal Abidin, Gong Badak Campus, 21300 Kuala Nerus, Terengganu, Malaysia \\ *Corresponding author E-mail: puadms@unisza.edu.my
}

\begin{abstract}
One of the important issues for sustainable island tourism is knowledge about the needs of the host and tourist. As tourism is now becoming a global issue, there is also a need to examine this issue from the context of a cross-culture. A better understanding of cultural dissimilarities between hosts and guests at certain areas of destinations could improve tailored services and increase satisfaction for both the host and tourists. Existing studies related to expectation mainly undertaken from the tourist view. However, this study takes into consideration the expectation of service quality from tourists' perspectives as well as host community. This study aims to gain some understanding about the impacts of cross-cultural dissimilarities between hosts and tourists by measuring their mutual expectations. Survey data is collected from Perhentian and Redang Islands, Malaysia. Two sample groups were involved in the study: host and tourists (Malay, Chinese, English and European). This study adopted two methods - the Mann-Whitney U-test and the Principal Components Analysis (PCA). The findings of this study demonstrate that mutual expectations between hosts and guests diverge across the cultural groups. This study contributes to the existing literatures related to service quality and highlights the importance of cultural differences in providing better quality tourism services particularly to island tourists in Malaysia and elsewhere.
\end{abstract}

Keywords: Host-Guest; Expectation; Service Quality; Small Island; Cross-Culture.

\section{Introduction}

Malaysia is blessed with abundant natural resources, including attractive small island destinations. To name a few - Tioman, Pangkor, Sipadan, Sibu, Lang Tengah, Tenggol, Perhentian and Redang. Island tourism is attractive to the long haul and potentially colder mid latitude markets of Europe, North America, Australia and New Zealand. However, visitors from these long haul markets significantly indicate cultural differences from the local community, whom they have a close contact in small island settings. Therefore, a study on cross-cultural exchange of the host and incoming tourists is particularly significant for Malaysia to increase understanding among the policy makers and local community on the cultural based demand and supply issue. The result of the study may be used by hosts to tailor the tourism products and services to fulfil tourists' needs and to increase satisfaction with their tourism experience. By understanding mutual expectation, sustainable tourism development not only can be achieved, it will also cause less adverse effects to the local communities.

Culture is characteristically a complex concept and literatures have defined it with hundreds of definitions. Culture can be distinguished using two important measurements, cultural values and rule of behavior. A value is a class of beliefs shared by members of society and focus upon what is good or bad or what should be and what should not be [1]. Values between hosts and guests have been recognized as critical values for comparison of cultures [2]. Values can be argued to cause behavior because they can determine the rules of behavior [3]. Therefore, differences in values replicate differences in behavior [4]. Rule of behavior defines acceptable and unacceptable behavior and these rules can diverse between different cultural groups, including subcultures within countries [5]. The relationship between the host/guest relationships can be improved by understanding the rules governing social relationships [6]. It is crucial to understand cultural differences in tourism as the differences may influence tourist behavior, travel destinations, activities involved and ultimately satisfaction and repeat visitation. As such, identifying cultural differences between hosts and guests are extremely important to develop strategies for successful marketing and market segmentation as well as ability to compete in a global market [7].

Expectations have been variously defined as "desires, wants, normative expectations, ideal standards, what the service provider should offer, and a pair of normative standards comprising what the consumer hopes to receive and adequate service" [8]. Expectations act as a comparison standard with perceptions which provide a relative measure of a customer's level of satisfaction [9]. "Knowing what customers expect is the first, and possibly most critical step in delivering service quality". Thus, in [10] asserted that expectation is what customers believe, based on the excellent service should be offered. In [10] also mentioned that the service expectations concept is intended to measure customers" normative expectations and that these expectations represent an "ideal standard" of performance. As a result, if the consumer's expectations are met, service quality is perceived satisfactory; and if it is not met, it is perceived to be less than satisfactory or else if exceeded, it is perceived delighting the customer [11].

In regards to tourism industry, competitiveness between tourism organization will rely on a professional approach to cause effect a tourism experience beyond tourists' expectations [12]. Moreover, 
if a tourism firm's core offering is able to meet the expectations of the customer, then tourist satisfaction can be achieved [13]. There was a research that compared customer expectations across different cultures [14]. Demographic profiles of those customers were studied to reflect the variance in expectations of service quality. Additional research indicated that demographics may have been responsible for the significant differences in the expectations of quality dimensions [15]. Existing research also suggested that cultural differences have an effect on the expectations of quality services. Most studies of tourist expectations are based on measurement of service quality [16] mix-matched expectations in tourism [13] and demand expectations in the tourism industry [12]. However, the study related to service quality expectation on island setting is still limited. In the context of studying the differences in expectations between two groups, hosts and guests become the significant area of study. Therefore, the primary objective of this study is to investigate the impacts of cross-cultural differences between host and tourist communities as measured by their mutual expectations.

\section{Methodology}

The aim of this study is to investigate the cultural differences between tourists and host communities in small island settings and the potential influences of culture on their mutual expectation. Perhentian and Redang Islands have been chosen to represent small islands because of their popularity and the most of tourist destination choice in Malaysia. The selection of these islands is also based upon the following:

i. The host communities on both islands are more committed to their customs and cultures, compared to the host communities in the west coast islands of Peninsular Malaysia and East Malaysia. Thus, the host communities on the east coast islands of Peninsular Malaysia, and in particular on Perhentian and Redang Islands are expected to be more sensitive to cultural issues.

ii. The majority of the local population on both islands are involved in tourism to make their living. It is expected that they are concerned to any issues related to the sustainability of the tourism industry.

iii. Perhentian and Redang are the most popular tourist destinations among the smaller Malaysian islands, and attract tourists with different cultures from all countries over the world.

Sample groups have been divided into 2 categories in order to measure the impact of culture: host and tourists (Malay, Chinese, English and European). The selection of these tourist group is based on the criteria of largest international tourist arrivals to the island destinations in Malaysia. A self-administered survey has been used as the main method and collected as a convenience sample. This study utilized a close-ended questionnaire. In order to measure the effect of cultural differences on expectation, 24 important variables related to the expectation of service quality were used. These variables represent 10 components of service quality: tangibles, reliability, responsiveness, competence, courtesy, credibility, security, accessibility, communication and understanding the customer. The variables chosen for this study are adopted from $[\mathbf{1 7}, \mathbf{1 8}]$. A 6-point Likert scale was used for all the 24 variables ranging from totally unimportant to totally important. Three types of analysis were adopted for this study. A descriptive analysis was used to summarize socio-demographic profiles of host and tourist groups. A Mann-Whitney U-test is used to examine the significant differences in individual variables of expectations between the cultural groups, while a Principal Components Analysis (PCA) was conducted to further explore the relationship between the variables and to identify groupings of expectations between hosts and guests.

\section{Findings and discussion}

This section presents the findings of the study in term of descriptive analysis and the Mann Whitney U-test, as well as a Principal Component Analysis (PCA). In total, 107 hosts were surveyed at Perhentian and Redang islands with all participating samples were Malay. However, there were also a few foreigners living on the islands and most of them working as dive masters. With regard to the language spoken, the majority of host communities on those islands spoke Malay. With reference to occupation, the largest two groups of hosts on Perhentian and Redang Islands worked in the accommodation sector. The other important sectors for hosts are food and beverage, sales, transport, professional management and other service work.

On the other hand, there were four sample groups of tourists chosen for this research; English, Non-English, Chinese and Malay. The non-English sample comprised of travelers from the Continental Europe. This study involved 514 tourist samples. The distribution of the three sample groups (Malay, Chinese and English) was evenly spread. The travelers from Continental European countries created the biggest group sample of the tourists because they are more approachable group as compared to the other three sample groups. Gender wise, slightly more than half of the sample were female. Tourists to these two islands were dominated by young travelers, aged between 21-30 years old.

The study findings, with reference to the Mann Whitney U-test have underlined significant differences in mutual expectations across the sample groups. These findings were then further investigated and confirmed using the Principal Component Analysis. The factor analysis was conducted with orthogonal (varimax) rotation to make the factor structure more interpretable.

The analysis of host expectation indicates that hosts emphasis on courtesy. Thus, the host seems to highlight some interest on good manner. Hosts also anticipate tourists to show some respect to them. Apart from that, host community emphasis on the importance of accessibility. In other word, host community on the island settings are looking forward to serve a friendly and approachable tourist. In order to offer a good service to the tourists, tourism operators also require island tourists be responsive, delivering correct information and being helpful. In addition, local hosts anticipate tourists to understand and respect their local culture and customs, especially issues related to dress code at their area. This is important because the majority of the local communities on these two islands are Muslim, thus issue of how to dress up is considered important to them.

On the other hand, island tourists seem to have different expectations when compared to the local hosts. In general, all four sample groups of tourist emphasis the same issues; understanding and accessibility. Therefore, island tourists expect host community to be proactive and could predict their needs, as well as being very friendly and paying full attention while serving them. The second important issues from the view of Chinese and Malay tourists are related to courtesy and competency. Being tourists, both of the tourist groups anticipate local host to deliver services to them in a polite manner and to treat them with respect. Service quality also measured by them on the local host's ability to provide quick and prompt service, as well as the ability of host to solve whatever problem faced by them.

Additionally, Chinese tourists also hoping that local hosts could communicate with them using Chinese language as most of them particularly from Mainland China has difficulty to converse in English.

Apart from understanding and accessibility issues, the English tourists appeared to focus on responsiveness. As such, they highlighted the local operators' skills in delivering services according to their needs and expectations.

Among the four sample groups of tourists, The European tourists portrayed a significant difference whereby they placed a great concern on understanding. Thus, they not only anticipate the local 
hosts' ability in understanding their needs and culture, but they also expect local hosts to converse in their language as most of them struggling to communicate in English. Tourists in general also eyeing the opportunity to mingle around with the local host community and learn about the islands' culture and customs.

\section{Conclusion}

Previous literatures emphasized on popular destinations and less studies have been done on small islands. As tourism experienced rapid development globally, cultural differences have become a critical issue to be addressed to understand the need of tourist and local service providers.

The findings of this study indicate that mutual expectation of hosts and tourists are different across cultural groups. If this issue is not well addressed, the differences will indirectly affect the attractiveness of that particular destination and will cause unnecessary misunderstanding between the hosts and tourists. Tourist understanding of the host culture is very significant to the local service providers. This issue should be addressed by the relevant stakeholders like tourist guide or tourism authority and spreading out the information in the brochures or other means of advertisement. On the other hand, tourists expect the host to provide better service quality. As such, relevant courses related to management and hospitality should be offered to the service providers on a continuous basis in order to improve efficiency and skills in providing good and quality services as expected by tourists. In addition, hosts should equip themselves with knowledge and information about different tourist culture as different cultural groups have different needs and expectations.

\section{Acknowledgement}

The authors would like to thank the Research Management, Innovation and Commercialization Centre, Universiti Sultan Zainal Abidin, Terengganu, Malaysia for providing the financial assistance to support the publication fee of this article.

\section{References}

[1] Pizam, A., \& Calantone, R. (1987). Beyond psychographicsVvalues as determinants of tourist behavior. International Journal of Hospitality Management, 6(3), 177-181.

[2] Reisinger, Y., \& Turner, L. W. (2003). Cross-cultural behaviour in tourism: Concepts and analysis. Butterworth-Heinemann.

[3] Samovar, L. A., \& Porter, R. E. (1988). Intercultural communication: A reader. Wadsworth Publishing Company.

[4] Rokeach, M. (1973). The nature of human values. Free Press.

[5] Harre, R., \& Secord, P. (1972). The explanation of social behavior. Basil Blackwell.

[6] Brislin, R. W. (1976). Cross-cultural orientation Programs. Wiley/Halsted.

[7] Reisinger, Y., \& Turner, L. W. (1997). Cross-cultural differences in tourism: Indonesian tourists in Australia. Tourism Management, 18(3), 139-147.

[8] Teas, R. K. (1994). Expectations as a comparison standard in measuring service quality: An assessment of a reassessment. Journal of Marketing, 58, 132-139.

[9] Cardozo, R. (1965). An experimental study of consumer effort, expectation and satisfaction. Journal of Marketing Research, 2(8), 244-249.

[10] Zeithaml, V. A., Parasuraman, A., \& Berry, L. L. (1990). Delivering quality service: Balancing customer perceptions and expectations. Simon and Schuster.

[11] Berry, L. L., Zeithmal, V. A., \& Parasuraman, A. (1985). Quality counts in services too. Business Horizons, 28(3), 44-52.

[12] Kandampully, J. (2000). The impact of demand fluctuation on the quality of service: A tourism industry example. Managing Service Quality: An International Journal, 10(1), 10-19.
[13] Lloyd, K. (2004). Tourism and transitional geographies: Mismatched expectations of tourism investment in Vietnam. Asia Pacific Viewpoint, 45(2), 197-215.

[14] Bebko, C. (2000). Service intangibility and its impact on consumer expectations of service quality. Journal of Services Marketing, 14(1), 9-26.

[15] Bebko, C., \& Prokop, R. (1996). Which consumers' expectations? SERVQUAL gap 1 analysis for non-professional services. Proceedings of the Northeast Decision Science Institute 25th Anniversary Conference.

[16] Khan, M. (2003). ECOSERV: Ecotourists' quality expectations. Annals of Tourism Research, 30(1), 109-124.

[17] Parasuraman, A., Zeithaml, V. A. \& Berry, L .L. (1985). A conceptual model of service quality and implications for future research. Journal of Marketing, 49, 41-50.

[18] Parasuraman, A., Zeithaml, V. A. \& Berry, L. L. (1988) SERVQUAL: A multiple-item scale for measuring consumer perceptions of service quality. Journal of Retailing, 64(1), 12-40. 